

\title{
Different operational alternatives of aquifer thermal energy storage system for cooling and heating of a residential complex under various climatic conditions in Iran
}

\author{
H. Ghaebi ${ }^{a, *}$, M.N. Bahadori ${ }^{b}$, and M.H. Saidi ${ }^{b}$ \\ a. Department of Mechanical Engineering, University of Mohaghegh Ardabili, University Blv., Ardabil, P.O. Box 179, Iran. \\ b. School of Mechanical Engineering, Sharif University of Technology, Azadi Ave., Tehran, P.O. Box 11155-9567, Iran. \\ Received 18 July 2016; received in revised form 28 May 2017; accepted 7 April 2018
}

\section{KEYWORDS \\ Aquifer thermal energy storage; \\ Climate; \\ Solar energy; \\ Heat pump.}

\begin{abstract}
In this research, a confined aquifer with low groundwater flow was considered to meet the cooling and heating requirements of residential complexes. The complexes were located in the cities of Ahvaz, Ardabil, Bandar Abbas, Esfahan, Kerman, Rasht, Tehran, and Zahedan. The complex in Ardabil mostly required heating, the ones in Ahvaz and Bandar Abbas mostly required cooling, and the complexes in other cities required both heating and cooling. Four different alternatives of Aquifer Thermal Energy Storage (ATES) were analyzed in this study. These alternatives consisted of using ATES: 1) alone for cooling, 2) coupled with a conventional refrigeration system or a chiller for cooling, 3) by employing flat plate solar collectors for heating, and 4) by employing flat plate solar collectors and a heat pump for heating. Thermal energy recovery factor and the annual Coefficient Of Performance (COP) of the alternatives were determined. The results showed that for buildings located in cities with mild climatic conditions (such as Esfahan), where the annual heating and cooling energy requirements were almost equal, the use of ATES would be highly recommendable, no matter through what alternative considered in this investigation.
\end{abstract}

(C) 2019 Sharif University of Technology. All rights reserved.

\section{Introduction}

Considering the issue of the relation between energy and buildings, sustainable engineering requires:

1. Reduction in the heating and cooling energy needs of buildings to their minimum possible values;

2. Reduction in consumption of primary sources of

*. Corresponding author.

E-mail addresses: hghaebi@uma.ac.ir (H. Ghaebi); bahadori@sharif.ir(M.N. Bahadori); saman@sharif.ir (M.H. Saidi)

doi: $10.24200 /$ sci. 2018.20323 energy to meet these minimum values through innovative design of energy conversion systems and the employment of innovative methods to meet the energy demands [1].

Aquifers are underground porous formations containing water. Confined aquifers are surrounded by impermeable layers, called cap rocks and bed rocks [1]. These aquifers are suitable for seasonal thermal energy storage. Seasonal storage of thermal energy in aquifers and utilization of solar energy and heat pumps are examples of innovative approaches to reducing the primary energy demand for heating and cooling of buildings in various climate conditions. Therefore, 
it is important to investigate under what climatic conditions the ATES system has the best performance.

Underground Thermal Energy Storage (TES) for cooling and heating of buildings has been employed in the United States [2-5], Europe [6-11], and other countries [12-15]. Recently, they have become more popular, considering the problems caused by the depletion of fossil fuels and the increase in global warming [16]. The ATES systems are generally considered as an economically viable tool for the seasonal storage of thermal energy [17]. In an ATES, contamination and depletion of groundwater are minimal, since the water withdrawn from aquifer is circulated through a heat exchanger, and is immediately injected back into the aquifer though injection well(s) [13].

The flow of groundwater and heat transfer has been meticulously discussed in hydrology. Kim et al. [14] employed thermo-hydraulic modeling to investigate the effects of parameters, such as the distance between the wells, hydraulic conductivity, and the rate of injection/withdrawal, on an ATES. They used Comsol software for numerical simulation. Sommer et al. [15] determined the thermal performance of largescale application of ATES using a simplified hydrogeological model. They compared the different zonation patterns and determined the influence of well-to-well distances. Jeon et al. [16] conducted a sensitivity analysis of recovery efficiency in two cases of hightemperature ATES system with a single well to select the key parameters. For a fractional factorial design used to choose input parameters with uniformity, they considered the optimal Latin hypercube sampling with an enhanced stochastic evolutionary algorithm. Bloemendal et al. [17] described what optimal and sustainable use of the subsurface would look like in relation to ATES systems. With simulations, they showed the impact of ATES systems on the subsurface and described the current way of dealing with these impacts in the Netherlands. Zeghicia et al. [18] assessed the suitability of using heat and cold storage in a single deep geothermal aquifer for district heating and cooling. They used an integrated modelling approach to evaluating the controls on the energy efficiency of High-Temperature Aquifer Thermal Energy Storage (HT-ATES). A parametric study of pressure distribution in a confined aquifer and thermal energy storage in aquifers employing heat pumps was reported by Ghaebi et al. [19]. Yi and Dong Ming [20] analyzed the effect of cold water storage in doublet-wells by analyzing the volume change of cold water body within different temperature ranges in different periods. They concluded that cold water storage in aquifers was viable. Gao et al. [21] investigated the well position for improving efficiency of thermal energy storage systems.

Using the ATES coupled to the other energy supply systems is a common method to satisfy energy demand of buildings. Paksoy et al. [22] utilized an ATES for air-conditioning of a supermarket on the Mediterranean coast of Turkey. This project was the first ATES application carried out in Turkey. Paksoy et al. [23] performed the feasibility study of the ATES system for heating and cooling of Cukurova University Balcali Hospital in Adana, Turkey. The system stored solar energy in the form of heat and winter coolness in an aquifer. Dincer and Dost [24] provided a perspective on using the TES in solar applications. One major project in Europe is the German parliament building, which employs TES and solar energy for heating [25]. Caliskan et al. [26] performed thermodynamic assessments of various thermal energy storage systems. They also conducted energy, exergy, and sustainability analyses of three various reference conditions. An experimental investigation into an aquifer thermal energy storage system was conducted in Belgium [27]. In that research, a low-temperature ATES system was coupled with heat pumps for heating and cooling of a hospital for a period of three years. Ghaebi et al. [28] investigated an ATES in combination with heat pump and solar collector for heating and cooling of a building complex located in Tehran.

Reveillerea et al. [29] estimated the geothermal contribution to the energy mix of a district heating network over time when using an ATES in Paris region. Their results showed that the ATES would provide 54 GWh per year for the heating system, or geothermal energy would provide $70 \%$ of the energy mix. Bakr et al. [30] conducted an analysis of a real case of multiple ATES systems. They considered the efficiency and the interference among systems installed in the city of The Hague, the Netherlands, in which a total of 19 ATES systems were installed within an area of about $3.8 \mathrm{~km}^{2}$ with a total of 76 operating wells. Kranz and Frick [31] discussed the characteristics of the ATES for building cooling of the German parliament buildings for almost 10 years. They concluded that by choosing proper operating conditions and design parameters, such as the temperature level of the cooling network or the regeneration temperature of the ATES, the efficiency of the considered system could be increased remarkably.

However, to our knowledge, no previous research has investigated the effect of climate on the performance of the ATES. In the present research, a suitable confined aquifer is considered to meet the cooling and heating requirements of a residential building complex located in cities of Ahvaz, Ardabil, Bandar Abbas, Esfahan, Kerman, Rasht, Tehran, and Zahedan in Iran. The hourly heating/cooling thermal energy requirements of these cities were estimated to come up with peak heating and cooling loads and the annual heating and cooling energy requirements. Because of extremely cold climate, the building complex in Ardabil needed only heating. The buildings in Bandar Abbas, 
with extremely hot and humid weather, and Ahvaz, with hot and dry weather, required only cooling. The building complexes located in the other cities required both heating and cooling. The sizes of the aquifers to meet the annual cooling and heating energy needs of the residential complexes located in these cities were determined. Ultimately, the recovery factors of the aquifers and COPs of the systems were compared for four different alternatives that were employed in different cities.

\section{Climate of Iran}

Plateau of Iran has been divided into 8 climatic regions [32]. The major cities representing these climates are: Ahvaz, Ardabil, Bandar Abbas, Esfahan, Kerman, Rasht, Tehran, and Zahedan:

- Region 1. Ardebil:

- Is located at high altitude above sea level compared to other regions;

- Is located at high geographic latitude;

- Has low minimum temperature and very cold winters;

- Mostly has snowfall;

- Is exposed to Siberian cold fronts and Mediterranean and Northern Europe humid fronts;

- Needs heating more than 45 percent of the year.

- Region 2. Kerman:

- Is located at high altitude above sea level compared to other regions;

- Is located at high geographic latitude;

- Has low minimum temperature (more than Region 1) and very cold and dry winters;

- Is exposed to Siberian cold fronts and Mediterranean and Northern Europe humid fronts;

- Needs heating about 40-45 percent of the year.

- Region 3. Esfahan:
- Is located at relatively low altitude above sea level;

- Has relatively low rainfall;

- Has a fluctuating temperature (cold nights and warm days);

- Has cold and dry winters;

- Needs heating about 30-40 percent of the year.

- Region 4. Rasht:

- Is located at relatively high geographic latitude;

- Has the maximum rainfall among all the regions;

- Has minimum temperature of about zero;

- Has mild and wet winters;

- Needs heating about 20 percent of the year.

- Region 5. Zahedan:

- Is located at low height over sea level;

- Has the minimum rainfall in Iran;

- Has a fluctuating temperature (cold nights and warm days);

- Has a mild and dry climate;

- Needs heating about 10-20 percent of the year.

- Region 6. Ahwaz:

- Is located at relatively low height over sea level;

- Is located at low latitudes;

- Has a semi-humid climate;

- Needs heating about 0-10 percent of the year.

- Region 7. Bandar Abbas:

- Is located at low latitudes;

- Has a humid climate;

- Needs heating about 0-5 percent of the year.

- Region 8. Tehran: In this climate, the conditions of the climates mentioned above can be seen together and the heating requirement is a combination of those in the climates of Regions $1,2,3$, and 4 .

Table 1 shows the locations and weather conditions of these cities.

Table 1. Weather conditions of the selected cities of Iran [33].

\begin{tabular}{|c|c|c|c|c|c|c|c|c|}
\hline \multirow[b]{2}{*}{ City } & \multirow[b]{2}{*}{$\begin{array}{c}\text { Latitude } \\
\quad\left({ }^{\circ}\right)\end{array}$} & \multirow[b]{2}{*}{$\begin{array}{c}\text { Longitude } \\
\left({ }^{\circ}\right)\end{array}$} & \multirow[b]{2}{*}{$\begin{array}{l}\text { Elevation } \\
\quad(\mathrm{m})\end{array}$} & \multicolumn{3}{|c|}{ Summer design } & \multicolumn{2}{|c|}{ Winter design } \\
\hline & & & & $\begin{array}{c}\text { DB } \\
\left({ }^{\circ} \mathrm{C}\right)\end{array}$ & $\begin{array}{l}\text { WB } \\
\left({ }^{\circ} \mathrm{C}\right)\end{array}$ & $\begin{array}{c}\text { Daily range } \\
(\mathrm{K})\end{array}$ & $\begin{array}{c}\text { DB } \\
\left({ }^{\circ} \mathrm{C}\right)\end{array}$ & $\begin{array}{l}\text { RH } \\
(\%)\end{array}$ \\
\hline Ahvaz & 31.2 & 48.5 & 12.2 & 46.4 & 27.8 & 17.8 & 2.8 & 80 \\
\hline Ardabil & 38.2 & 48.2 & 1310.6 & 29.7 & 20.3 & 16.1 & -21.9 & 78 \\
\hline Bandar Abbas & 27.2 & 56.3 & 10.1 & 40.6 & 31.9 & 9.4 & 5.5 & 87 \\
\hline Esfahan & 32 & 51 & 1600.2 & 36.9 & 16.1 & 21.1 & -10.8 & 80 \\
\hline Kerman & 30.1 & 57.1 & 1749.6 & 36.4 & 15.4 & 17.8 & -11.4 & 73 \\
\hline Rasht & 37.2 & 49.4 & -3.7 & 31.9 & 25.7 & 9.2 & -2.2 & 92 \\
\hline Tehran & 35.7 & 51.4 & 1219.8 & 38.9 & 23.9 & 15 & -6.7 & 77 \\
\hline Zahedan & 29.5 & 60 & 1350.3 & 37.5 & 17.2 & 16.7 & -6.9 & 70 \\
\hline
\end{tabular}


Table 2. Heating and cooling requirements of the residential complex in the selected cities.

\begin{tabular}{lcccc}
\hline \multicolumn{1}{c}{ City } & $\begin{array}{c}\text { Peak } \\
\text { heating } \\
\text { load } \\
(\mathbf{M W})\end{array}$ & $\begin{array}{c}\text { Peak } \\
\text { cooling } \\
\text { load } \\
(\mathbf{M W})\end{array}$ & $\begin{array}{c}\text { Annual } \\
\text { cooling } \\
\text { requirement } \\
\mathbf{( T J )}\end{array}$ & $\begin{array}{c}\text { Annual } \\
\text { heating } \\
\text { requirement } \\
\text { (TJ) }\end{array}$ \\
\hline Ahvaz & 0 & 1.78 & 22.4 & 0 \\
Ardabil & 1.250 & 0.32 & 0.75 & 9.56 \\
Bandar Abbas & 0 & 1.96 & 29.6 & 0 \\
Esfahan & 0.965 & 0.75 & 4.76 & 5.37 \\
Kerman & 0.856 & 0.77 & 5.97 & 3.51 \\
Rasht & 0.11 & 1.2 & 7.38 & 3.23 \\
Tehran & 0.471 & 1.3 & 8.7 & 1.9 \\
Zahedan & 0.475 & 0.89 & 7.29 & 2.65 \\
\hline
\end{tabular}

\section{Specifications of the residential complexes}

The specifications of the investigated residential complexes were taken from Ref. [28].

Hourly cooling and heating energy needs of the buildings were estimated using the HAP 4.41 (Carrier) software. Table 2 shows the peak heating and cooling loads as well as the annual heating and cooling energy requirements of the building complexes located in the considered cities.

\section{Different alternatives of operation}

We considered four alternatives to meet the heating and cooling energy requirements of the building complexes. These alternatives were: cooling through ATES alone, cooling through ATES augmented with a chiller, heating through ATES and employing flat plate solar collectors, and finally heating through ATES coupled to flat plate solar collectors and heat pump(s). These alternatives are briefly described below [28].

\subsection{Cooling through ATES alone}

In this alternative, water is withdrawn from the aquifer in winter and after cooling by one or more cooling towers, it is injected back into the aquifer. The cold water is stored for summer use. In summer, cold water is withdrawn from the aquifer and by going through a heat exchanger, the cooling needs of the residential complex are satisfied. Figure 1 shows the operation of the system in this alternative.

\subsection{Cooling through ATES coupled with a chiller}

Figure 2 schematically shows operation of the system in this alternative. This alternative is employed in cities with extreme cooling load, where the ATES alone cannot meet the cooling requirements. The chiller is selected by considering the refrigeration load and chiller evaporator supply temperature (withdrawn through

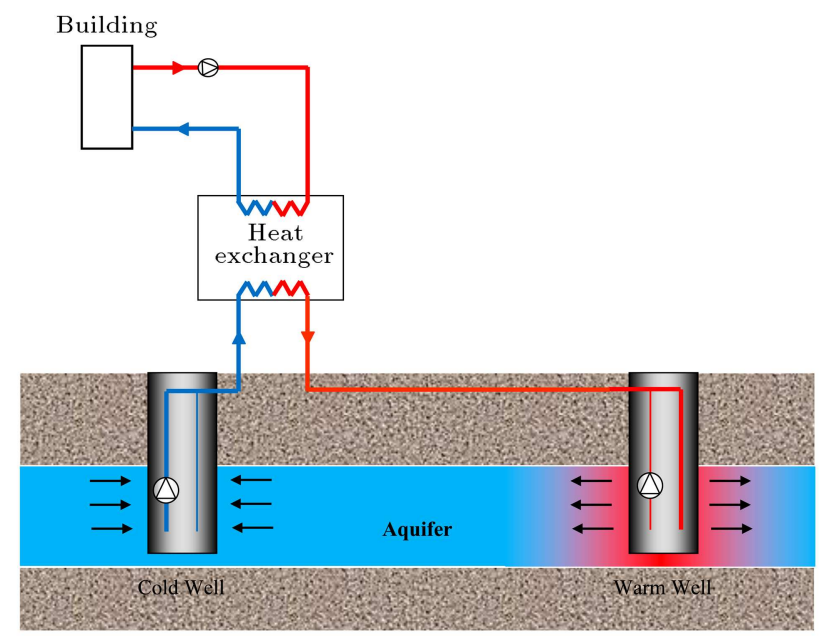

(a)



(b)

Figure 1. Cooling through ATES alone: (a) Summer and (b) winter.

cold well), and by assuming $7^{\circ} \mathrm{C}$ temperature rise in chilled water according to the catalogue [34].

\subsection{Heating through ATES employing flat plate solar collectors}

Figure 3 shows an ATES coupled with flat plate solar 


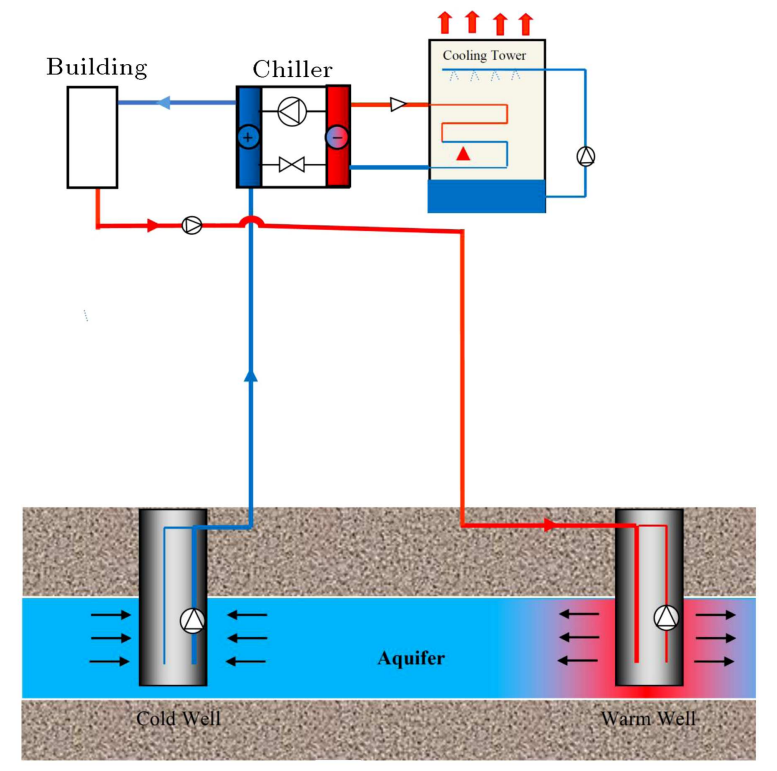

(a)

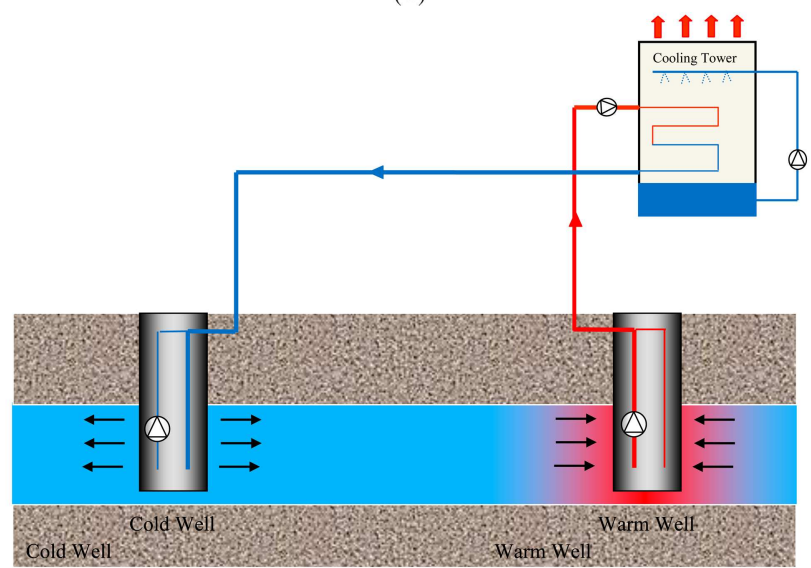

(b)

Figure 2. Cooling through ATES augmented with chiller(s): (a) Summer and (b) winter.

collectors. In this system, solar energy is utilized during the summer months to heat the water withdrawn from the aquifer. The heated water is then injected back into the aquifer. The stored warm water is withdrawn in winter to meet the heating needs of the building [1].

\subsection{Heating through ATES and employing flat plate solar collectors and heat pump $(s)$}

In regions where the stored solar energy alone cannot meet the heating requirements, we can employ heat pumps. Figure 4 schematically shows the operation of this alternative.

\section{Mathematical formulation}

Thermo-hydraulic analysis of the aquifer performance requires calculation of the groundwater flow and the temperature distribution in the aquifer and its sur-

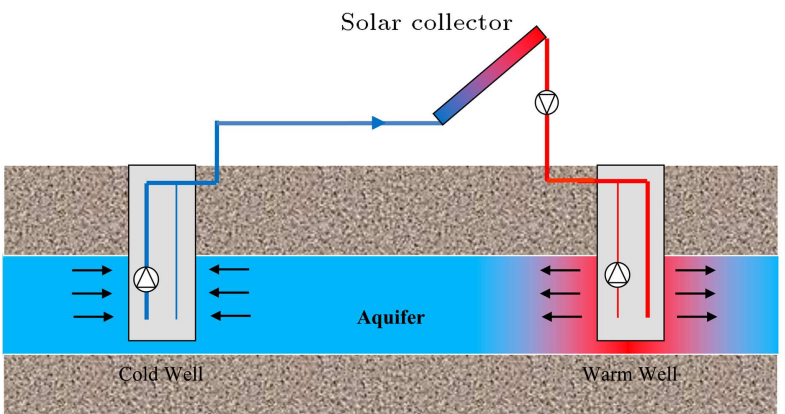

(a)



(b)

Figure 3. Heating through ATES employing flat plate solar collectors: (a) Summer and (b) winter.

rounding layers. In this section, theoretical principles of water flow and heat transfer phenomena for calculating temperature distribution inside the aquifer are explained. The coupled groundwater and heat flow are governed by the partial differential equations describing mass and energy balances in the aquifer [1].

Aquifer is a porous medium. The continuity equation in a porous medium may be expressed by the following equation [35]:

$$
\left[\frac{\partial(\rho \phi)}{\partial t}+\vec{\nabla} \cdot(\rho \vec{q})\right] d V=S_{f}
$$

where $S_{f}$ is related to source/sink term inside the porous medium and $\vec{q}$ is a flow flux vector. It is obtained from the Darcy's equation:

$$
\vec{q}=-K \vec{\nabla} h
$$

This equation is the governing equation for the flow in a porous medium. In this equation, $K$ is the aquifer permeability.

Pressure drop between the wells is calculated by 




(a)



(b)

Figure 4. Heating through ATES and employing flat plate solar collectors and heat pump(s): (a) Summer and (b) winter.

the following equation [35]:

$$
\Delta h_{S P}=\frac{Q}{2 \pi K b} \operatorname{Ln} \frac{r_{o}}{r_{W}} .
$$

$r_{o}$ and $r_{W}$ are halves of the distances between wells and the radii of wells, respectively.

The equation for heat transfer (conduction and convection) is derived by applying the energy conservation principle in a porous medium $[36,37]$ :

$$
\begin{aligned}
& p_{s} \frac{\partial T}{\partial t}=\nabla^{2}(\lambda T)-(\rho c)_{f} \vec{q} \cdot \vec{\nabla} T+S_{H}, \\
& p_{s}=(\rho c)_{f} \phi+(\rho c)_{S}(1-\phi),
\end{aligned}
$$

where $p_{s},(\rho c)_{f}$, and $(\rho c)_{S}$ are heat capacities per unit volume of aquifer, water, and the pebbles, respectively. In Eq. (4), $T, q$, and $S_{H}$ are temperature, specific velocity, and energy source/sink terms inside the aquifer, respectively, while $\lambda$ is a combined ratio that is a function of the thermal conductivity of water, pebbles, and aquifer porosity [28]:

$$
\lambda=\phi k_{f}+(1-\phi) k_{s} .
$$

Thermo-physical properties of water and aquifer were used from [28].

The heat transfer phenomenon within the upper and lower surrounding layers of the aquifer is mainly conduction. Therefore, we have [28]:

$$
\frac{\partial T}{\partial t}=\alpha \nabla^{2} T
$$

\section{Numerical modeling}

The numerical modeling including solution method, meshing, initial and boundary conditions, and model assumptions have been comprehensively investigated in Ref. [28].

\section{Discussion of the Results}

\subsection{Model verification}

The model has been verified as discussed in [28].

\subsection{Using different alternatives of ATES for heating and cooling of the selected cities}

For modeling and design, initial data are needed as the inputs. These input data are given in Table 3.

Design simulation is carried out as explained in Section 5. The results of the design simulation are listed in Table 4.

In air conditioning systems, COP is an important factor for performance evaluation. COP is equal to the amount of the annual heating/cooling requirements divided by the total power consumption of the system, e.g., pumps, cooling towers fans, heat pumps, etc. The pump embedded in the aquifer should have the power to overcome all the pressure losses through the pipes and heat exchanger(s), and inside the aquifer. For an accurate assessment, it is assumed that the piping and water transmission system on the surface are the same for all cities. The pressure losses were determined considering $250 \mathrm{~m}$ straight pipes, 10 elbows, a pipe diameter of $10 \mathrm{~cm}$, a diameter of $2.5 \mathrm{~cm}$ and a length of $5 \mathrm{~m}$ for the tubes in the shell and tube heat exchanger, and finally $45 \mathrm{~m}$ for the depth of the aquifer wells. Table 5 shows the pressure losses in different alternatives for various cities.

\subsubsection{ATES alone for cooling}

Figure 5 shows the annual power consumption for different cities. As it is seen, it has the highest value in Bandar Abbas due to high cooling requirements, injection/withdrawal flow rates, and pressure losses. As a result, the power consumption by the pump and the cooling tower fans is higher in this city than in other cities. 
Table 3. Input data for design of the ATES system.

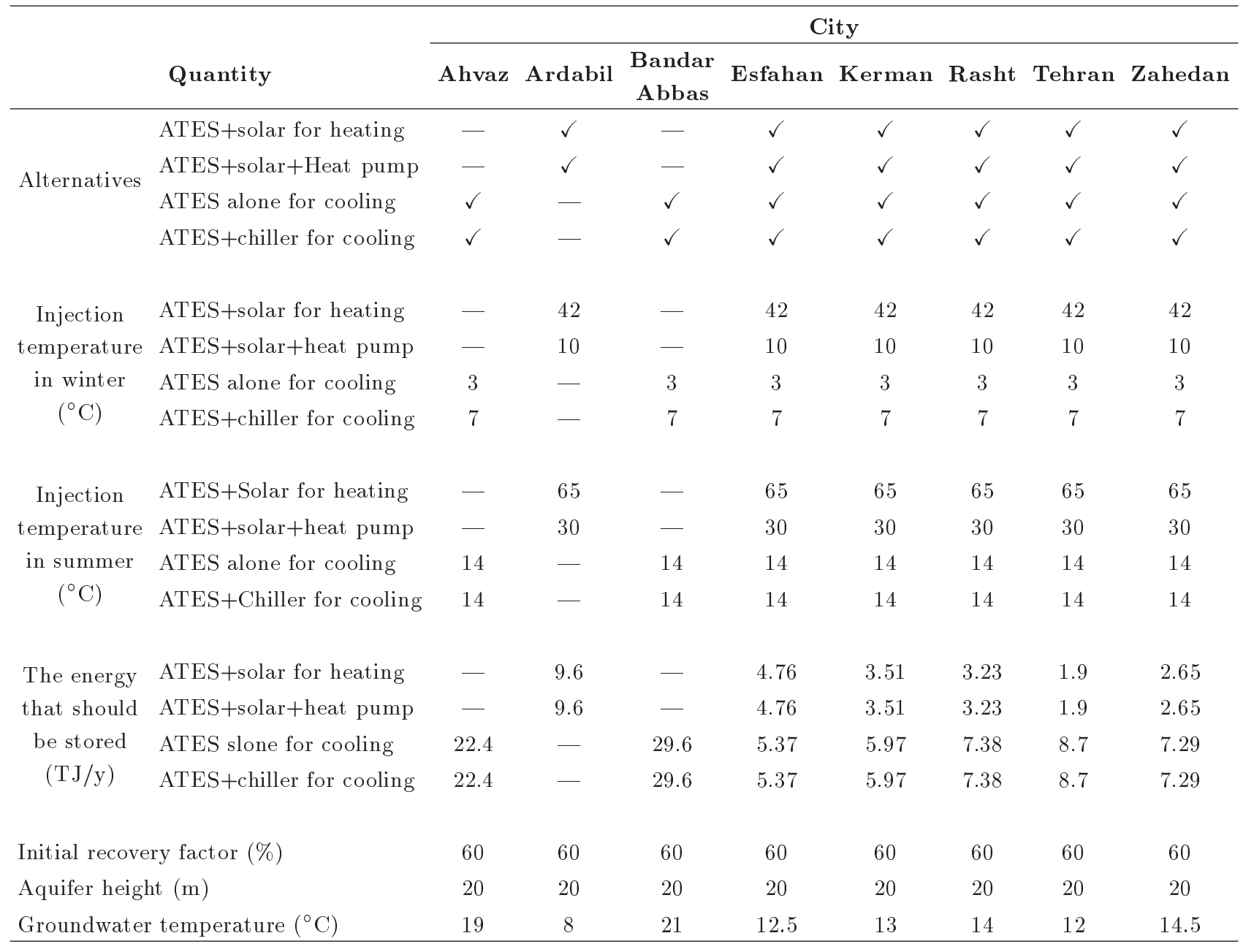

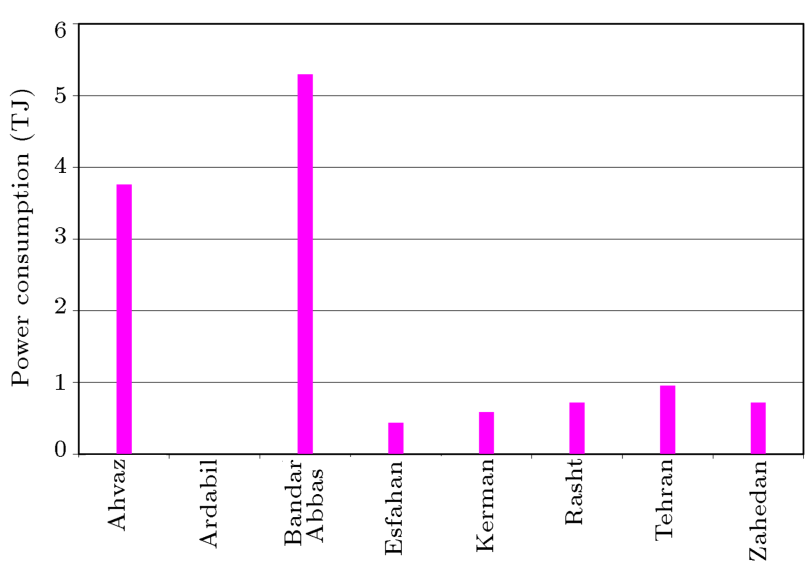

Figure 5. Comparison of annual power consumption for the ATES alone alternative.

Figure 6 shows the recovery factor and COP for this alternative. Both $\eta_{A}$ and COP for Esfahan are higher than those for Bandar Abbas. Groundwater temperature in Esfahan is lower than that in Bandar Abbas. This leads to lower heat transfer from the

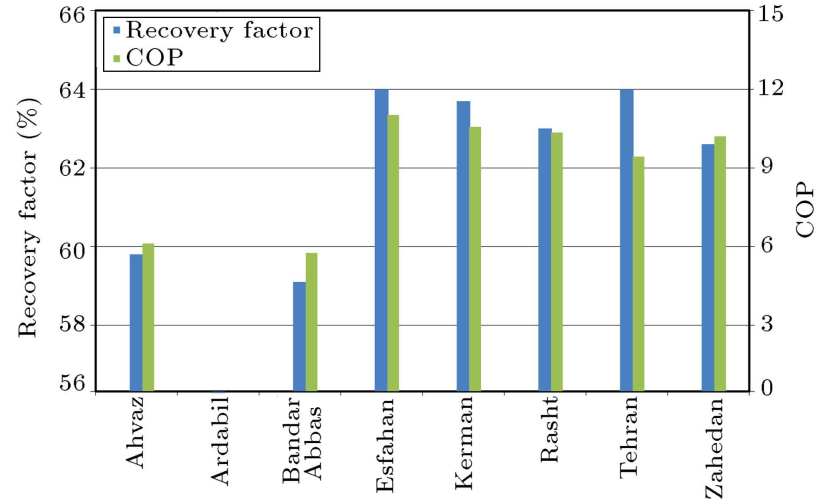

Figure 6. Comparison of $\eta_{A}$ and COP for the ATES alone alternative.

aquifer located in Esfahan than that located in Bandar Abbas.

\subsubsection{Coupling of ATES with chiller for cooling}

The annual power consumption for this alternative is shown in Figure 7. Similar to the ATES alone alternative, the power consumption by the pumps, 
Table 4. Results of the different alternatives for different climates.

\begin{tabular}{|c|c|c|c|c|c|c|c|c|c|}
\hline & \multirow[b]{2}{*}{ Quantity } & \multicolumn{8}{|c|}{ City } \\
\hline & & Ahvaz & Ardabil & $\begin{array}{c}\text { Bandar } \\
\text { Abbas }\end{array}$ & Esfahan & Kerman & Rasht & Tehran & Zahedan \\
\hline \multirow{4}{*}{$\begin{array}{l}\text { Aquifer } \\
\text { length } \\
(\mathrm{m})\end{array}$} & ATES+solar for heating & - & 124 & - & 102 & 92 & 90 & 76 & 84 \\
\hline & ATES+solar+heat pump & - & 130 & - & 106 & 96 & 94 & 80 & 88 \\
\hline & ATES alone for cooling & 240 & - & 270 & 128 & 140 & 152 & 162 & 152 \\
\hline & ATES+chiller for cooling & 292 & - & 330 & 154 & 178 & 182 & 194 & 182 \\
\hline \multirow{4}{*}{$\begin{array}{l}\text { Aquifer } \\
\text { width } \\
(\mathrm{m})\end{array}$} & ATES+solar for heating & - & 72 & - & 48 & 36 & 32 & 24 & 30 \\
\hline & ATES+solar+heat pump & - & 80 & - & 56 & 40 & 36 & 26 & 32 \\
\hline & ATES alone for cooling & 180 & - & 212 & 72 & 82 & 94 & 104 & 92 \\
\hline & ATES+chiller for cooling & 234 & - & 274 & 96 & 102 & 124 & 136 & 122 \\
\hline \multirow{4}{*}{$\begin{array}{l}\text { Injection } \\
\text { rate } \\
\left(\frac{\mathrm{L}}{\mathrm{s}}\right)\end{array}$} & ATES+solar for heating & - & 18.33 & - & 8.83 & 5.76 & 5.03 & 3.12 & 4.35 \\
\hline & ATES+solar+heat pump & - & 21.08 & - & 10.16 & 6.63 & 6.1 & 3.59 & 5 \\
\hline & ATES alone for cooling & 47.87 & - & 63.28 & 14.25 & 17.86 & 22.08 & 26.03 & 21.81 \\
\hline & ATES+chiller for cooling & 75.23 & - & 99.45 & 22.39 & 28 & 34.7 & 40.91 & 34.28 \\
\hline \multirow{4}{*}{$\begin{array}{c}\text { Withdrawal } \\
\text { rate } \\
\left(\frac{\mathrm{L}}{\mathrm{s}}\right)\end{array}$} & ATES+solar for heating & - & 9.78 & - & 7.69 & 5.02 & 4.62 & 2.71 & 3.79 \\
\hline & ATES+solar+heat pump & - & 11.24 & - & 7.08 & 5.77 & 5.31 & 3.12 & 4.36 \\
\hline & ATES alone for cooling & 26.72 & - & 42.64 & 12.22 & 13.4 & 18.54 & 23.3 & 17.45 \\
\hline & ATES+chiller for cooling & 41.99 & - & 79.96 & 16.31 & 15.67 & 19.36 & 22.83 & 19.13 \\
\hline \multirow{4}{*}{$\begin{array}{l}\text { Distance of } \\
\text { the wells } \\
(\mathrm{m})\end{array}$} & ATES+solar for heating & - & 92 & - & 70 & 56 & 54 & 40 & 48 \\
\hline & ATES+solar+heat pump & - & 98 & - & 74 & 60 & 58 & 44 & 52 \\
\hline & ATES alone for cooling & 204 & - & 212 & 92 & 104 & 116 & 126 & 116 \\
\hline & ATES+chiller for cooling & 256 & - & 274 & 118 & 132 & 146 & 154 & 146 \\
\hline
\end{tabular}

Table 5. Pressure losses in the aquifer to be employed in different cities.

\begin{tabular}{|c|c|c|c|c|c|c|c|c|c|}
\hline & \multirow[b]{2}{*}{ Quantity } & \multicolumn{8}{|c|}{ City } \\
\hline & & Ahvaz & Ardabil & $\begin{array}{c}\text { Bandar } \\
\text { Abbas }\end{array}$ & Esfahan & Kerman & Rasht & Tehran & Zahedan \\
\hline \multirow{4}{*}{$\begin{array}{c}\Delta P_{\text {Well pairs }} \\
\quad(\mathrm{m})\end{array}$} & ATES+solar for heating & - & 0.41 & - & 0.18 & 0.11 & 0.1 & 0.057 & 0.083 \\
\hline & ATES+solar+Heat pump & - & 0.47 & - & 0.21 & 0.14 & 0.12 & 0.067 & 0.098 \\
\hline & ATES alone for cooling & 1.24 & - & 1.68 & 0.32 & 0.4 & 0.51 & 0.61 & 0.51 \\
\hline & ATES+chiller for cooling & 2.03 & - & 2.75 & 0.53 & 0.68 & 0.84 & 1 & 0.84 \\
\hline
\end{tabular}

chiller, and the fans in Bandar Abbas is higher than that in the other cities.

The recovery factor $\left(\eta_{A}\right)$ and the COP in this alternative are shown in Figure 8. As mentioned above, $\eta_{A}$ in Esfahan is higher than those in the other cities. This is due to lower groundwater temperature inside the aquifer in this city. The COP for Esfahan is also high. When compared with the ATES alone alternative, $\mathrm{COP}$ is low in this alternative because of the extra power consumption by the chiller.

\subsubsection{Heating by employing flat plate solar collectors} Figure 9 shows the power consumption of the system for this alternative in different cities. It is seen that the power consumption in the ATES system designed for Ardabil is higher than that for the other cities. 




Figure 7. Comparison of power consumption for ATES coupled with a chiller.



Figure 8. Comparison of $\eta_{A}$ and COP for ATES coupled with a chiller for cooling.

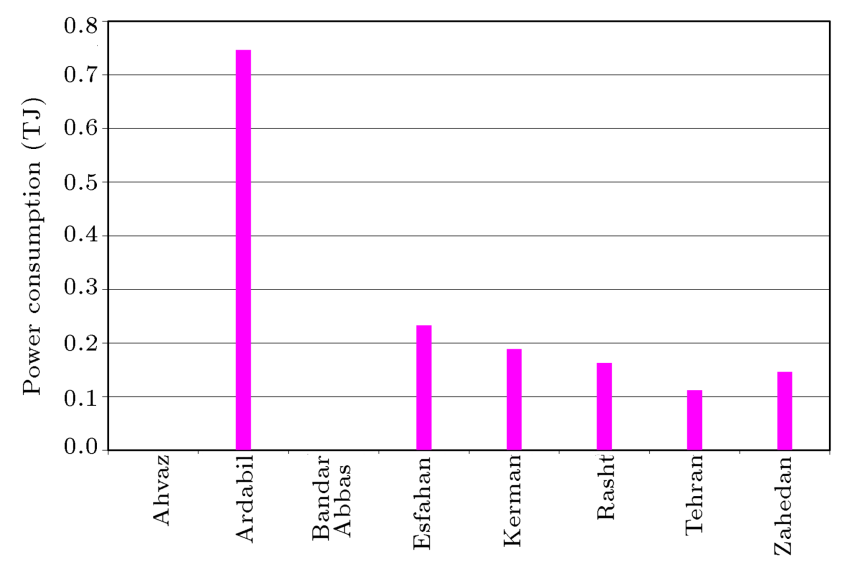

Figure 9. Power consumption in the ATES employing flat plate solar collectors for heating.

This is due to the higher injection/withdrawal water flow rate in this city.

Figure 10 shows $\eta_{A}$ and COP in this alternative. The difference between injection temperature

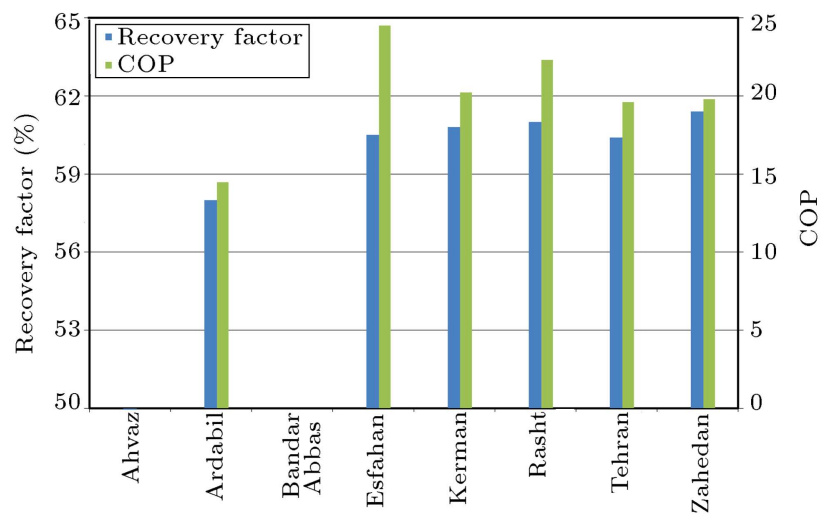

Figure 10. Comparison of $\eta_{A}$ and COP in the ATES employing flat plate solar collectors for heating.



Figure 11. Power consumption in the ATES coupled with flat plate solar collectors and a heat pump.

and groundwater temperatures is too high. Therefore, heat losses in this alternative are higher than those in the other considered alternatives employed for heating. Due to higher temperature difference inside the aquifer located in Ardabil, there is more heat dissipation. As a result, the recovery factor is lower than those in the other cities. The COP is also lower in Ardabil because of higher power consumption.

\subsubsection{Heating by coupling of ATES with flat plate solar collectors and a heat pump}

Figure 11 shows the power consumption of the ATES system in this alternative. Due to high pressure drop compared to the solar heating alternative, the power consumption is higher in this alternative.

The difference between injection temperature and groundwater temperature is lower in this alternative. Therefore, the recovery factor $\eta_{A}$ is the highest for all the cities in this heating alternative among all the alternatives (Figure 12).

\section{Conclusions}

In this study, the performance of an ATES under 




Figure 12. Comparison of the $\eta_{A}$ and COP in the ATES coupled with flat plate solar collectors and a heat pump.

four different operational alternatives was evaluated for different climates of Iran using a numerical simulation. These alternatives were:

1. ATES alone for cooling;

2. ATES coupled with a chiller for cooling;

3. ATES coupled with flat plate solar collectors for heating;

4. ATES coupled with flat plate solar collectors and heat pump for heating.

The cities of Ahvaz, Ardabil, Bandar Abbas, Esfahan, Kerman, Rasht, Tehran, and Zahedan were selected as representatives of the 8 climatic conditions of Iran. A residential building complex was considered and was assumed to be located in any of these cities. The peak heating/cooling demands and the annual heating/cooling energy needs of the complex were estimated under the climatic conditions of these cities.

The following concluding remarks can be made in this investigation:

- In the ATES alone for cooling alternative, the recovery factor and COP of the system for Esfahan were higher than those for the other cities;

- In the ATES coupled with a chiller for cooling, both the recovery factor and COP of the system for Esfahan were higher than those for the other cities;

- In the ATES coupled with flat plate solar collectors for heating alternative, the recovery factor and COP of the system for Esfahan were higher than those for the other cities;

- In the ATES coupled with flat plate solar collectors and a heat pump for heating alternative, the recovery factor and COP of the system for Esfahan were higher than those for the other cities;

- For large buildings located in cities with mild climatic conditions, where the annual heating and cooling energy requirements are nearly the same, the use of the ATES is highly recommended by employing any of the alternatives considered in this investigation and discussed above.



\section{Greek symbols}

$\begin{array}{ll}\alpha & \text { Diffusivity }\left(\mathrm{m}^{2} / \mathrm{s}\right) \\ \eta & \text { Efficiency or recovery factor } \\ \varphi & \text { Porosity } \\ \lambda & \text { Aquifer thermal conductivity }(\mathrm{W} / \mathrm{m} / \mathrm{k}) \\ \rho & \text { Density }\left(\mathrm{kg} / \mathrm{m}^{3}\right)\end{array}$

\section{Subscripts}

$\begin{array}{ll}A & \text { Aquifer } \\ F & \text { Fluid } \\ H & \text { Heat } \\ i m p & \text { Imposed } \\ \text { injection } & \text { Injection } \\ r e q & \text { Required } \\ S & \text { Specific, solid } \\ \text { Storage } & \text { Storage } \\ \text { System } & \text { System } \\ \text { Withdraw } & \text { Withdrawal }\end{array}$

\section{References}

1. Ghaebi, H., Bahadori, M.N., and Saidi, M.H. "Economic and environmental evaluation of different operation alternatives to aquifer thermal energy storage in Tehran, Iran", Scientia Iranica, Transactions B: Mechanical Engineering, 24, pp. 610-623 (2017). 
2. Meyer, C.F. and Todd, D.K. "Heat storage wells", Water Well Journal, 10, pp. 35-41 (1973).

3. Molz, F.J., Warman, J.C., and Jones, T.E. "Aquifer storage of heated water: Part 1: A field experiment", Ground Water, 16, pp. 234-241 (1978).

4. Papadopulos, S.S. and Larson, S.P. "Aquifer storage of heated water: Part 2: numerical simulation of field results", Ground Water, 16, pp. 242-248 (1978).

5. Parr, D.A., Molz, F.J., and Melville, J.G. "Field determination of aquifer thermal energy storage parameters", Ground Water, 21, pp. 22-35 (1983).

6. Andersson, O., Hellstrom, G., and Nordell, B. "Heating and cooling with UTES in Sweden-current situation and potential market development", International Proceedings of the 9th International Conference on Thermal Energy Storage, Warsaw, Poland, 1, pp. 359366 (2003).

7. Sanner, B., Karytsas, C., Mendrinos, D., and Rybach, L. "Current status of ground source heat pumps and underground thermal energy storage in europe", Geothermics, 32, pp. 579-588 (2003).

8. Paksoy, H.O., Andersson, O., Abaci, S., Evliya, H., and Turgut, B. "Heating and cooling of a hospital using solar energy coupled with seasonal thermal energy storage in an aquifer", Renewable Energy, 19, pp. 117$122(2000)$.

9. Dickinson, J.S., Buik, N., Matthews, M.C., and Snijders, A. "Aquifer thermal energy: Theoretical and operational analysis", Geotechnique, 59, pp. 249-260 (2009).

10. Novo, V.A., Bayon, R.J., Castro-Fresno, D., and Rodriguez-Hernandez, R. "Review of seasonal heat storage in large basins: Water tanks and gravel water pits", Applied Energy, 87, pp. 390-397 (2010).

11. Preene, M. and Powrie, W. "Ground energy systems: Delivering the potential", Energy, 34, pp. 77-84 (2009).

12. Umemiya, H. and Satoh, Y. "A cogeneration system for a heavy snow fall zone based on aquifer thermal energy storage", Japanese Society of Mechanical Engineering, 13, pp. 757-765 (1993).

13. Gao, Q., Li, M., Yu, M., Spitler, J.D., and Yan, Y.Y. "Review of development from GSHP to UTES in China and other countries", Renewable Sustainable Energy Reviews, 13, pp. 1383-1394 (2009).

14. Kim, J., Lee, Y., Yoon, W.S., Jeon, J.S., Koo, M.H., and Keehm, Y. "Numerical modeling of aquifer thermal energy storage system", Energy, 35, pp. 49554965 (2010).

15. Sommer, W., Valstar, J., Leusbrock, I., Grotenhuis, T., and Rijnaarts, H. "Optimization and spatial pattern of large-scale aquifer thermal energy storage", Applied Energy, 137, pp. 322-337 (2015).
16. Jeon, J.S., Lee, S.R., Pasquinelli, L., and Fabricius, I.L. "Sensitivity analysis of recovery efficiency in hightemperature aquifer thermal energy storage with single well”, Energy, 90, pp. 1349-1359 (2015).

17. Bloemendal, M., Olsthoorn, Th., and Boons, F. "How to achieve optimal and sustainable use of the subsurface for aquifer thermal energy storage", Energy Policy, 66, pp. 104-114 (2014).

18. Zeghicia, R.M., Essink., G.H.P.O., Hartogc, N., and Sommer, W. "Integrated assessment of variable density-viscosity groundwater flow for a high temperature mono-well aquifer thermal energy storage (HTATES) system in a geothermal reservoir", Geothermics, 55, pp. 58-68 (2015).

19. Ghaebi, H., Bahadori, M.N., and Saidi, M.H. "Parametric study of the pressure distribution in a confined aquifer employed for seasonal thermal energy storage", Scientia Iranica, Transactions B: Mechanical Engineering, 22, pp. 235-244 (2015).

20. Yi, ZH. and Dong Ming, G. "Effect of cold energy storage of doublet-well aquifer thermal energy storage in Sanhejian coal mine", Energy Proceedings, 14, pp. 1730-1734 (2012).

21. Gao, Q., Zhou, X.Zh., Jiang, Y., Chen, X.L., and Yan, Y.Y. "Numerical simulation of the thermal interaction between pumping and injecting well groups", Applied Thermal Engineering, 51, pp. 10-19 (2013).

22. Paksoy, H.O., Gurbuz, Z., Turgut, B., Dikici, D., and Evliya, H. "Aquifer thermal storage (ATES) for air conditioning of a supermarket in Turkey", Renewable Energy, 29, pp. 1991-1996 (2004).

23. Paksoy, H.O., Andersson, O., Abaci, S., Evliya, H., and Turgut, B. "Heating and cooling of a hospital using solar energy coupled with seasonal thermal energy storage in an aquifer", Renewable Energy, 19, pp. 117122 (2000).

24. Dincer, I. and Dost, S. "A perspective on thermal energy storage system for solar energy applications", International Journal of Energy Research, 20, pp. 547557 (1996).

25. Bauer, D., Marx, R., Lux, J.N., Ochs, F., Heidemann, W., and Steinhagen, H.M. "German central solar heating plants with seasonal heat storage", Solar Energy, 84, pp. 612-623 (2010).

26. Caliskan, H., Dincer, I., and Hepbasli, A. "Thermodynamic analyses and assessments of various thermal energy storage systems for buildings", Energy Conversion and Management, 62, pp. 109-122 (2012).

27. Vanhoudta, D., Desmedta, J., Van Baela, J., Robeynb, N., and Hoe, H. "An aquifer thermal storage system in a Belgian hospital: Long-term experimental evaluation of energy and cost savings", Energy and Buildings, 43, pp. 3657-3665 (2011).

28. Ghaebi, H., Bahadori, M.N., and Saidi, M.H. "Performance analysis and parametric study of thermal energy storage in an aquifer coupled with a heat pump", Applied Thermal Engineering, 62, pp. 156-170 (2014). 
29. Reveillerea, A., Hamm, V., Lesueur, H., Cordier, E., and Goblet, P. "Geothermal contribution to the energy mix of a heating network when using aquifer thermal energy storage: Modeling and application to the paris basin", Geothermics, 47, pp. 69-79 (2013).

30. Bakr, M., Oostrom, N., and Sommer, W. "Efficiency of and interference among multiple aquifer thermal energy storage systems; A Dutch case study", Renewable Energy, 60, pp. 53-62 (2013).

31. Kranz, S. and Frick, S. "Efficient cooling energy supply with aquifer thermal energy storages", Applied Energy, 109, pp. 321-327 (2013).

32. Hannani, S.K. "Climate classification in Iran", Technical Report, Sharif University of Technology, Tehran, Iran (2001) (In Persian).

33. Iran Meteorological Organization, http://www.irimo. ir (In Persian).

34. www.ssi.co.ir (Accessed 30 October 2016).

35. Bear, J., Dynamics of Fluids in Porous Media, Elsevier, Dover Publication Inc., pp. 450-510 (1992).

36. Bejan, A., Convective Heat Transfer, McGraw Hill Press, New York (1997).

37. Schaetzle, W.J., Thermal Energy Storage in Aquifers, Design and Applications, Pergamon Press, Oxford, UK (1980).

\section{Biographies}

Hadi Ghaebi is Assistant Professor in the Mechanical Engineering Faculty of the Mohaghegh Ardabili University, Ardabil, Iran. He received his PhD degree from Sharif University of Technology, Tehran, Iran in 2014. His research areas include thermal system design and optimization, renewable energy technologies, net zero energy buildings, and hydrogen and fuel cells.

Mehdi N. Bahadori received his $\mathrm{PhD}$ degree in Mechanical Engineering from the University of Illinois, USA, in 1964, and is currently Professor of Mechanical Engineering at Sharif University of Technology, Tehran, Iran. His research interests include natural cooling systems, solar energy utilization, environmentally compatible energy systems, development of indigenous technology, application of scientific-spiritual thinking to social problems, entropy and awareness, and engineering ethics and engineering of ethics.

Mohammad Hassan Saidi is Professor in the School of Mechanical Engineering at Sharif University of Technology, Tehran, Iran. His current research interests include MEMS, heat transfer enhancement in boiling and condensation, modeling of pulse tube refrigeration, vortex tube refrigerators, indoor air quality and clean room technology, energy efficiency in home appliances, and desiccant cooling systems. 